Editorial

\title{
Laser Watch-New Generation 2021: Modern Integrative Photomedicine Equipment for Photobiomodulation
}

\author{
Gerhard Litscher *
}

Research Unit for Complementary and Integrative Laser Medicine, Research Unit of Biomedical Engineering in Anesthesia and Intensive Care Medicine, and Traditional Chinese Medicine (TCM) Research Center Graz, Medical University of Graz, 8036 Graz, Austria; E-Mail: gerhard.litscher@medunigraz.at

* Correspondence: Gerhard Litscher; E-Mail: gerhard.litscher@medunigraz.at

Collection: Trends in Acupuncture and Laser Research and Education

OBM Integrative and Complementary Medicine

2021, volume 6 , issue 4

doi:10.21926/obm.icm.2104037
Received: October 18, 2021

Accepted: October 18, 2021

Published: October 22, 2021

\begin{abstract}
In the recent past, laser therapy has made immense progress as it is known to change microcirculation, modulate vegetative parameters, and stimulate mitochondrial activity in the human body. This editorial briefly describes a new laser watch prototype (generation 2021), which can be used to perform continuous and simultaneous blood irradiation at the radial and/or ulnar artery of the wrist with different wavelengths of laser light. In a preliminary measurement, the increase in regional oxygen saturation at the crook of the elbow during laser light stimulation with the watch was observed using near-infrared spectroscopy. Apart from this, laser stimulation applied via a newly designed laser watch can modulate biological parameters (photobiomodulation). However, presently, the possible long-term effects are not known, as there are no studies on this topic available to date.
\end{abstract}

\section{Keywords}

Laser watch; photobiomodulation (PBM); laser; laser blood irradiation; light; integrative and complementary medicine; near-infrared spectroscopy (NIRS); regional oxygen saturation $\left(\mathrm{rSO}_{2}\right)$

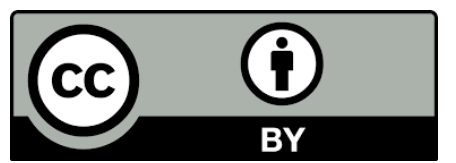

(C) 2020 by the author. This is an open access article distributed under the conditions of the Creative Commons by Attribution License, which permits unrestricted use, distribution, and reproduction in any medium or format, provided the original work is correctly cited. 


\section{Introduction}

More than five years have passed since the publication of the first two articles on the term "laser watch" by the author of this editorial [1,2]. Only two further articles, one in an unlisted journal [3], have dealt with this topic [3, 4]. During this period, at least four more generations of the so-called laser watch were brought into the international market, mainly in China and Germany. The fact that the laser watch constitutes a new and promising therapeutic approach for different diseases is undisputed; however, its practical implementation seems extremely difficult due to the lack of published scientific data on these photo stimulation watches.

In this editorial, the prototype of a newly developed laser watch (Figure 1) is described briefly, which can be used for non-invasive blood irradiation at the radial and ulnar arteries with different wavelengths; it can also deliver a laser dose that is many times higher than that of previous comparable stimulation watches [1-4]. The first presentation of this prototype equipment (EndoLight ${ }^{\circledR}$ ) from Weber Medical (Lauenförde, Germany) should take place in the context of this editorial, since photobiomodulation (PBM) in connection with, for example, COVID-19 is an important topic of current discussions among scientists [3-11].

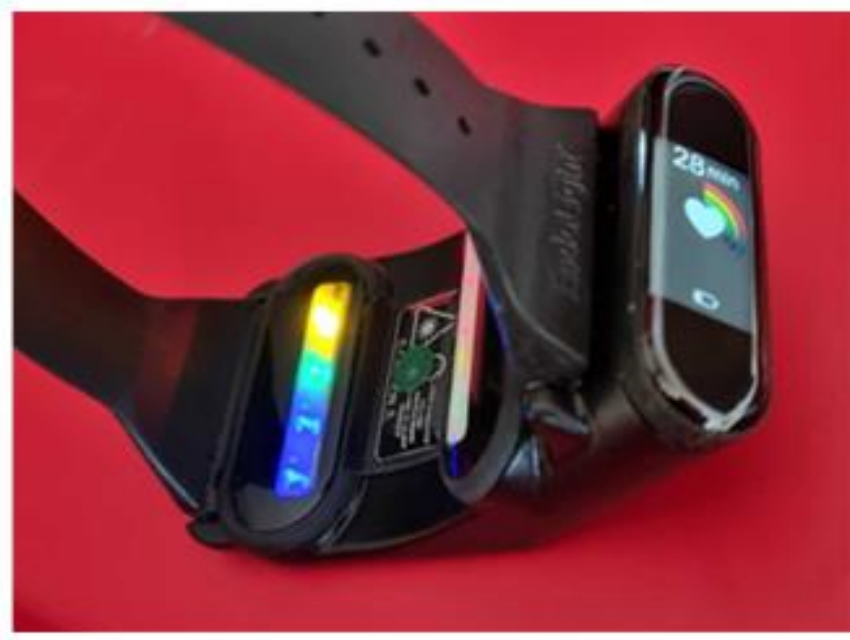

a

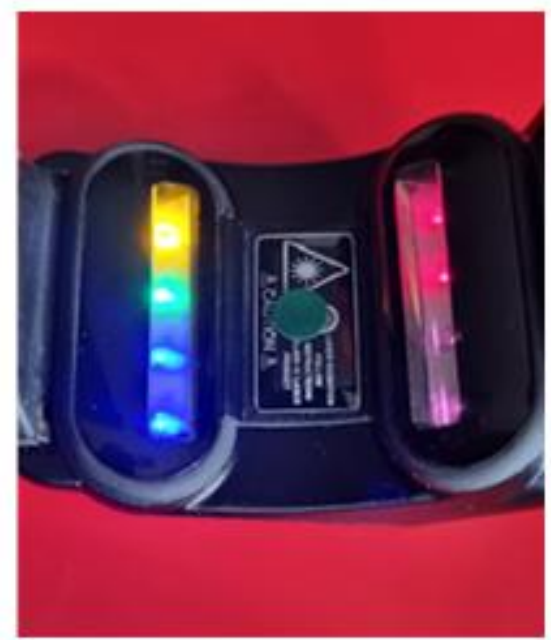

b

Figure 1 a, b: Laser watch prototype of the new generation 2021; the watch is assigned to laser Class $1 \mathrm{C}$ (please note that the interruption of the laser stimulation by the green area is cancelled for demonstration purposes). All figures (C) G. Litscher, October 14, 2021.

\section{Methods}

The new laser watch prototype (Figure 2 ) is a Class 1 C laser category product, as mentioned in the legend of Figure 1 . These laser products are explicitly designed for contact application on the skin or non-ocular tissue. During operation, any eye hazards must be prevented with the help of technical measures (i. e., the design of the laser-emitting equipment should not damage the eyes of 
the patient or other people). In addition, the exposure levels can exceed the maximum permissible exposure (MPE) of the skin (level of laser radiation to which people can be exposed under normal circumstances without any impairment), provided that this is necessary for the intended treatment method. Please note that Class $1 \mathrm{C}$ is a new category of laser products [12] and, therefore, the related data cannot be found in older textbooks or publications [13].

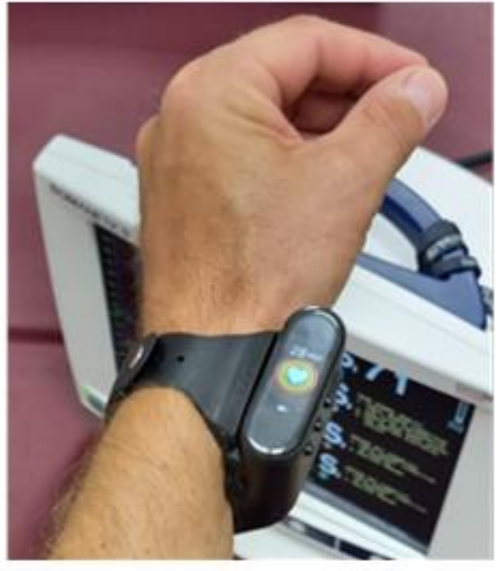

a

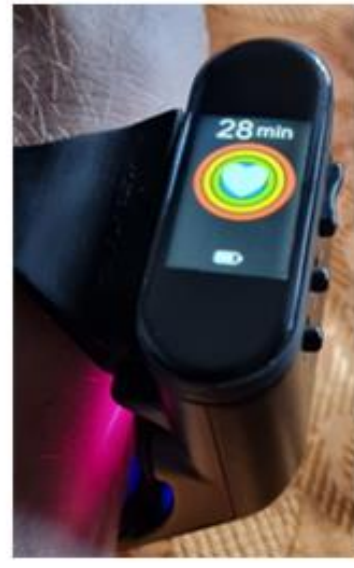

b

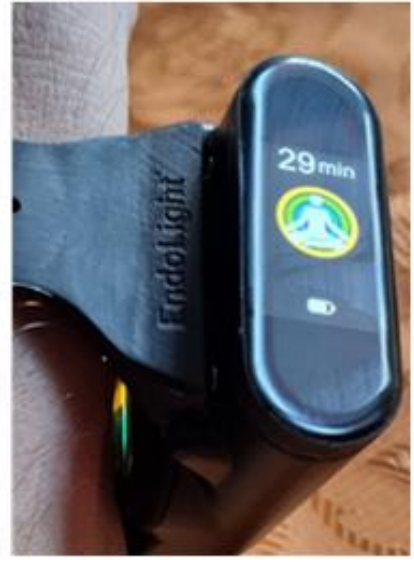

C

Figure 2 a-c: The new laser watch in practical research use (a). It supplies infrared light and red light, (b) but other wavelengths (green, blue, and yellow) are also available simultaneously or individually (c).

The technical details have not (yet) been disclosed by Weber Medical; however, information about the intensity ( $35 \mathrm{~mW}$ ) per laser has been personally communicated to this author. With this prototype, irradiation with the following wavelengths is possible: red $(658 \mathrm{~nm})$, with a penetration depth of about 2-4 cm; infrared $(808 \mathrm{~nm}$ ), with a penetration depth of about 3-4 cm; yellow (590 $\mathrm{nm})$, with a penetration depth of about $3 \mathrm{~cm}$; green $(505 \mathrm{~nm})$, with a penetration depth of about $0.5-1 \mathrm{~cm}$; and blue $(450 \mathrm{~nm})$, with a penetration depth of about $0.5-2 \mathrm{~mm}$ [14].

A pilot measurement of the changes in regional oxygen saturation $\left(\mathrm{rSO}_{2}\right)$ was performed with an INVOS 5100C Oximeter (Somanetics Corp., Troy, MI, USA) on October 14, 2021 (Figure 3a). In this measurement, near-infrared light $(730 \mathrm{~nm}$ and $805 \mathrm{~nm}$ ) was made to pass through the skin at the crook of the elbow (Figure $3 b$ ), and, after passing through different kinds of tissue, the reflected light was detected at two distances from the light source $(3 \mathrm{~cm}$ and $4 \mathrm{~cm})$. The spectral absorption of the blood in deeper structures $(2-4 \mathrm{~cm})$ was determined and defined as the $\mathrm{rSO}_{2}$ values [15]. 


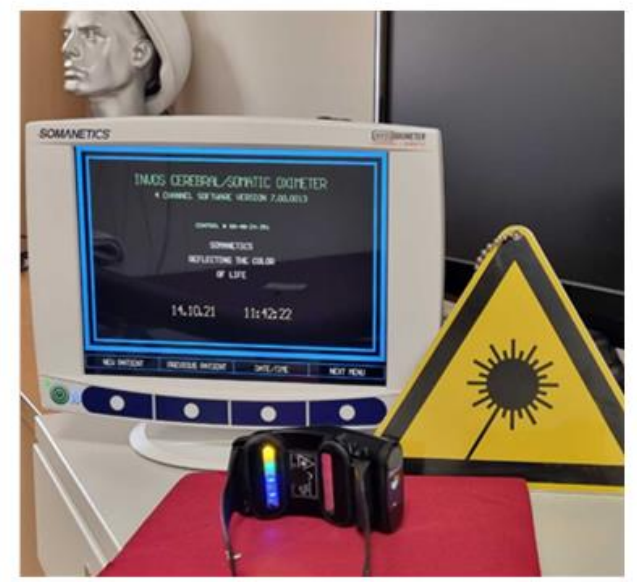

a

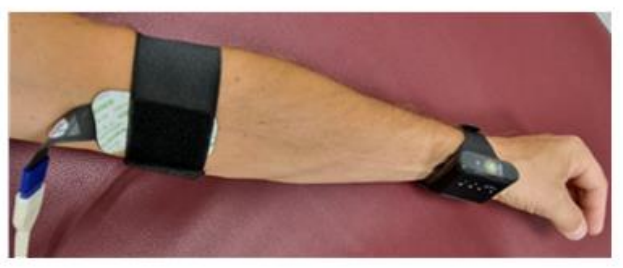

b

Figure 3 a, b: INVOS 5100C Oximeter (Somanetics Corp., Troy, MI, USA) (a). Laser stimulation is performed at the wrist (b). The $\mathrm{rSO}_{2}$ sensor is applied at the crook of the elbow (b).

\section{Preliminary Results}

The purpose of this preliminary measurement, which was carried out with near-infrared spectroscopy (NIRS), was to investigate peripheral $\mathrm{rSO}_{2}$ for the first time, before, during, and immediately after laser watch stimulation. The results indicate that the $\mathrm{rSO}_{2}$ values were significantly higher during laser watch blood irradiation of the radial and ulnar artery with the different available wavelengths (see methods section) as compared to the baseline values before stimulation (Figure 4).

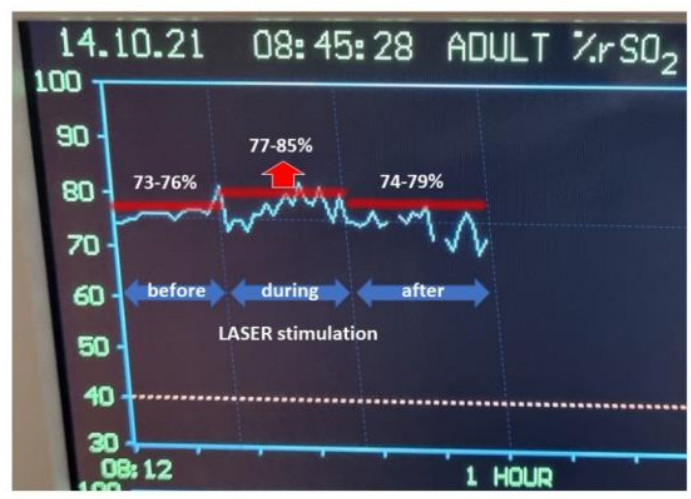

Figure 4 Continuous $\mathrm{rSO}_{2}$ measurement values in percentage before, during, and after laser watch stimulation at the wrist of the left arm, which was recorded in the crook of the left elbow. Note the increase during the stimulation period with a duration of about $10 \mathrm{~min}$. 


\section{Discussion}

Even if the author of this work is convinced that direct laser light stimulation can change blood oxygenation [14-22], it should be noted that there are still many unanswered questions on the subject. PBM can be used to treat and/or alleviate certain disease conditions [23-26], but technical parameters like power density, the duration of the exposure, the frequency of the light, and many others are largely undetermined. It is, therefore, the author's conviction that further research needs to be carried out before these methods can find broad clinical application in mainstream medicine.

The quality of scientific experiments is determined by the incorporation of appropriate controls. This applies in particular to PBM, regardless of whether it is a highly sophisticated large-scale device or a comparably simple stimulation device that can be used as a wristwatch. A non-critical use should be expressly waived before any conclusions are drawn and published. As already mentioned in the introduction, there is still a lack of published knowledge on so-called laser watches. Even if the first pilot measurements show positive effects [1, 2], it is important to prove their reproducibility in smaller test series as well as their clinical significance in large-scale studies.

\section{Conclusion}

For the first time, a newly designed sophisticated laser watch prototype (generation 2021) is presented. The preliminary results indicate an increase in peripheral $\mathrm{rSO}_{2}$ during and immediately after using the laser watch stimulation in a single far-field-recording session. Of course, no statement can be made about possible long-term effects, since this would certainly require at least a comprehensive investigation, which was not the goal of this editorial. However, this could be the subject of follow-up studies and could potentially be included in a controlled and/or cross-over research study design.

\section{Acknowledgments}

The author wishes to thank Robert Weber, MSc and Michael Weber, MD for provision of a prototype of a laser watch of the new generation (2021) for research purposes and for the consent to be able to publish results with the prototype.

\section{Author Contributions}

The author did all the research work of this study.

\section{Funding}

TCM Research Center Graz, Medical University of Graz.

\section{Competing Interests}

The author hereby declares that no conflict of interests exists in connection with the publication of this article. No funding has been received from Weber Medical (Lauenförde, Germany) or any other company developing this laser watch prototype. 


\section{References}

1. Litscher G, Litscher D. A laser watch for simultaneous laser blood irradiation and laser acupuncture at the wrist. Integr Med Int. 2016; 3: 75-81.

2. Litscher $D$, Litscher $G$. Laseruhr - simultane laserakupunktur und laserblutbestrahlung am handgelenk. Akupunkt Aurikulomed. 2015; 4: 32-36.

3. Weber HM, Mehran YZ, Orthaber A, Saadat HH, Weber R, Wojcik M. Successful reduction of SARS-CoV-2 viral load by photodynamic therapy (PDT) verified by QPCR - a novel approach in treating patients in early infection stages. Med Clin Res. 2020; 5: 311-325.

4. Weber M, Mehran YZ, Orthaber A, Saadat HH, Weber R, Wojcik M. Anti-viral photodynamic therapy in Covid-19 management: A novel approach in treating patients in early infection stages. Akupunkt Aurikulomed. 2021; 47: 29-34.

5. Litscher G. Can laser medicine and laser acupuncture be used for COVID-19? Selected areas of the current scientific literature. OBM Integr Complement Med. 2020; 5: 1-6.

6. Enwemeka CS, Bumah VV, Masson-Meyers DS. Light as a potential treatment for pandemic coronavirus infections: A perspective. J Photochem Photobiol B Biol. 2020; 207: 111891.

7. Li M, Yang X, Li K, Xie YQ. Traditional Chinese Medicine for novel coronavirus pneumonia treatment: Main force or supplement? Tradit Med Res. 2020; 5: 62-64.

8. Domínguez A, Velásquez SA, David MA. Can transdermal photobiomodulation help us at the time of COVID-19? Photobiomodul Photomed Laser Surg. 2020; 38: 258-259.

9. Fekrazad R. Photobiomodulation and antiviral photodynamic therapy as a possible novel approach in COVID-19 management. Photobiomodul Photomed Laser Surg. 2020; 38: 255-257.

10. Fernandes $A B$, Lima $C J$, Villaverde $A G$, Pereira $P C$, Carvalho $H C$, Zângaro RA. Photobiomodulation: Shining light on COVID-19. Photobiomodul Photomed Laser Surg. 2020; 38: 395-397.

11. Ferreira MV. Response to: Can transdermal photobiomodulation help us at the time of COVID19? Photobiomodul Photomed Laser Surg. 2020; 38: 326-327.

12. Laser safety FAQ - frequently asked questions [Internet]. Switzerland: Laserworld; 2015 [cited date 2021 October 16]. Available from: https://www.laserworld.com/en/laser-safetyfaq/2964-laser-classes.html.

13. Litscher G. Technical aspects of laser acupuncture. In: Laser acupuncture and laser medicine. Munich, Germany: Bahr \& Füchtenbusch; 2018; Chapter 2: 5-12.

14. Litscher G, Zhang X, Sheng Z, Jing XH, Wang L. Multimodal laser stimulation and traditional needle acupuncture in post-stroke patients - a pilot cross-over study with results from near infrared spectroscopy. Medicines. 2019; 6: 115.

15. Litscher G, Schwarz G. Transcranial cerebral oximetry. Lengerich, Germany: Pabst Science Publisher; 1997.

16. Litscher G, Ofner M, He W, Wang L, Gaischek I. Acupressure at the meridian acupoint Xiyangguan (GB33) influences near-infrared spectroscopic parameters (regional oxygen saturation) in deeper tissue of the knee in healthy volunteers. Evid Based Complementary Altern Med. 2013; 2013: 1-5.

17. Széles JC, Litscher G. Objectivation of cerebral effects with a new continuous electrical auricular stimulation technique for pain management. Neurol Res. 2004; 26: 797-800. 
18. Litscher G. Effects of popliteal illumination on cerebral near-infrared spectroscopy. Neurol Res. 2001; 23: 807-809.

19. Schwarz G, Litscher G, Sandner-Kiesling A. Pseudoparadoxical dissociation of cerebral oxygen saturation and cerebral blood flow velocity after acupuncture in a woman with cerebrovascular dementia: A case report. Neurol Res. 2004; 26: 698-701.

20. Hadolt I, Litscher G. Noninvasive assessment of cerebral oxygenation during high altitude trekking in the Nepal Himalayas (2850-5600 m). Neurol Res. 2003; 25: 183-188.

21. Litscher G, Schwarz G, Ratzenhofer-Komenda B, Kovac H, Gabor S, Smolle-Jüttner FM. Transcranial cerebral oximetry in the hyperbaric environment. Biomed Tech (Berl). 1997; 42: 38-41.

22. Litscher G, Schwarz G, Jobstmann R, Klein G, Neumann I, Prietl B. Noninvasive monitoring of regional cerebral oxygen saturation - experiences in critical care medicine. Biomed Tech (Berl). 1995; 40: 70-75.

23. Ailioaie LM, Litscher G. Probiotics, photobiomodulation, and disease management: Controversies and challenges. Int J Mol Sci. 2021; 22: 4942.

24. Ailioaie LM, Litscher G. Curcumin and photobiomodulation in chronic viral hepatitis and hepatocellular carcinoma. Int J Mol Sci. 2020; 21: 7150.

25. Ailioaie LM, Litscher G. Molecular and cellular mechanisms of arthritis in children and adults: New perspectives on applied photobiomodulation. Int J Mol Sci. 2020; 21: 6565.

26. Litscher G, Ailioaie LM. Comments on new integrative photomedicine equipment for photobiomodulation and COVID-19. Photonics. 2021; 8: 303.

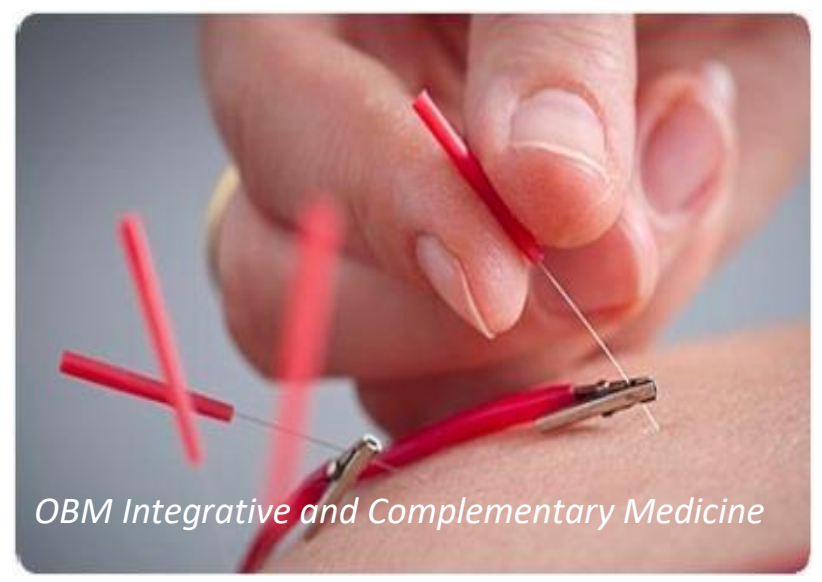

Enjoy OBM Integrative and Complementary Medicine by:

1. Submitting a manuscript

2. Joining in volunteer reviewer bank

3. Joining Editorial Board

4. Guest editing a special issue

For more details, please visit: http://www.lidsen.com/journals/icm 